\title{
O ESTADO DE DIREITO E OS REGIMES AUTORITÁRIOS: VIESES CONTEMPORÂNEOS NA AMÉRICA LATINA $^{1}$
}

THE STATE OF LAW AND THE AUTHORITARIAN REGIMES: CONTEMPORARY BIASES ON LATIN AMERICA

Pamela de Carvalho Magalhães ${ }^{2}$

Manoel Ilson Codeiro ROCHA ${ }^{3}$

ISSUE DOI: $10.21207 / 2675-0104.2018 .742$

\begin{abstract}
RESUMO
O objetivo principal desse trabalho é demonstrar que o neopopulismo, uma continuação do populismo do século XX que se adequa tanto ao Estado de Direito, quanto ao regime autoritário, contém igualmente um viés autoritário pelo caráter manipulativo de seu discurso com a utilização do "carisma" pelo líder populista, o que permite a sua convivência tumultuada com o princípio da legalidade na América Latina. Com esse estudo, não se pretende esgotar o assunto abordado, mas expor a possibilidade dessa convivência entre lei e neopopulismo e a importância de que os limites legais sejam respeitados e não excedidos para preservar a ordem democrática.
\end{abstract}

Palavras-chave: Autoritarismo. Estado de Direito. Neopopulismo. América Latina.

\footnotetext{
${ }^{1} \mathrm{O}$ presente artigo sintetiza a monografia de conclusão da pesquisa, realizada para o Programa Interno de Bolsas de Iniciação Científica (PIBIC 2017-2018) da Faculdade de Direito de Franca (FDF), Franca/SP.

${ }^{2}$ Discente da Faculdade de Direito de Franca (FDF), Franca/SP. Bolsista do Programa Interno de Bolsas de Iniciação Científica (PIBIC 2017-2018).

${ }^{3}$ Graduado em Direito pela Universidade Estadual Paulista-UNESP (1996). Mestre em Direito Público pela Universidade Estadual Paulista - UNESP (2000). Doutor em Direito Administrativo pela Universidade de Lisboa - UL (2015). Atualmente é professor de Direito Internacional na Faculdade de Direito de Franca.
} 


\section{ABSTRACT}

At last, the aim of this work is to demonstrate that the neo-populism, a continuation from the populism from the XX century which suits the State Law and the authoritarianism, holds an authoritarian biases by its manipulative speech and charisma by a popular leader which allows a troubled interaction with principle of legality on Latin America. With this work, the aim is not to exhaust the matter, but to demonstrate the possibility of coexistence of Law and neo-populism, and the importance that the limits exist to be respected in order to maintain the democratic order.

Keywords: Authoritarianism. Law State. Neo-populism. Latin America.

\section{INTRODUÇÃO}

O presente trabalho tem por objetivo a elaboração de uma reflexão interdisciplinar entre as áreas da ciência política e do Direito sobre os vieses autoritários presentes na América Latina, mais especificamente os do populismo e neopopulismo, utilizados tradicionalmente nesse conjunto de países para romper ou burlar a ordem democrática.

O tema da pesquisa foi delimitado visando oferecer conhecimento conceitual e histórico sobre os regimes autoritários e o Estado de Direito, sendo que, embora sejam caracterizados comumente como antagônicos, há a possibilidade de existirem vieses autoritários no Estado em que impera o princípio da legalidade. Além disso, há uma reflexão sobre a relação do populismo e do neopopulismo, se há, ou não, um viés autoritário no segundo como no primeiro, com essa possibilidade de convivência de autoritarismo e legalidade na América Latina.

A metodologia utilizada nessa pesquisa consiste no levantamento interdisciplinar bibliográfico sobre o tema em livros e artigos científicos dos cursos de ciência política, história e Direito para se estabelecer os conceitos necessários para alcançar seu objetivo.

Dessa maneira foi realizada uma pesquisa bibliográfica para produzir conhecimentos sobre a figura do Regime Autoritário, o Estado de Direito e o viés autoritário presente nas suas instituições na contemporaneidade e, por fim, foi analisado o conceito de populismo e a diferença quando comparado ao neopopulismo, além de ser verificado se neste, assim como no anterior, existem iguais indicativos da presença de um viés autoritário, o que, com a figura da democracia representativa fragilizada por estar passando por um processo de desgaste nos últimos anos, poderia ser utilizado por líderes políticos carismáticos para abusarem e se manterem no poder. 
O regime autoritário em sentido amplo é todo regime antidemocrático. Nele, o poder de decidir e se fazer obedecer do governo, é concentrado na mão de uma única pessoa ou grupo, que o exerce destruindo a ideia da igualdade entre os cidadão e diminuindo ou extinguindo a participação popular na política, geralmente por meios coercitivos, logo, a figura de autoridade do governo aparenta ser legítima, mas não é.

O regime autoritário alega ter uma legitimidade social para existir, entretanto a própria existência do autoritarismo implica a de um sentimento de descrença na autoridade do governante e desaprovação do exercício do poder, que nasce quando governante e governado sentem que um é desleal com o outro. O primeiro, por acreditar que detém a legitimidade e deve ser obedecido, exerce o poder que the foi concedido arbitrariamente contra o segundo, que não concorda com as suas ordens, se sente traído em virtude de ter as expectativas que depositou no governante frustradas e tem a sua participação política diminuída ou excluída.

Max Weber discorre que a política é um campo que faz uso do meio da violência, afinal o Estado comumente é o único que pode praticar o que chamamos de violência legítima, ressalvando apenas algumas exceções permitidas por aquele como a legítima defesa. Entretanto explica que, ao contrário do que ocorre em regimes autoritários que transferem a culpa pelo uso da violência para autoridade, os fins não justificam os meios e o ideal seria ter no comando de um Estado um político que assume a responsabilidade pelos próprios atos.

\footnotetext{
Normalmente, em contrapartida, o protestantismo legitimou de maneira absoluta o Estado, ou seja, o meio da violência enquanto instituição divina, legitimando também, em particular, o Estado autoritário. Lutero retirou a responsabilidade ética pela guerra do particular e o transferiu para a autoridade. Obedecer à autoridade em outras questões para além das questões de fé nunca podia constituir culpa. ${ }^{4}$
}

No autoritarismo, quando a culpa é retirada do particular e transferida para a autoridade, alimenta-se a máquina autoritária e "legitima-se" por meio disso o regime. Os indivíduos não acreditam que estejam fazendo algo errado por ser em nome da vontade da autoridade

\footnotetext{
${ }^{4}$ WEBER, Max. Ciência e Política: Duas Vocações. Tradução de e notas: Marco Antonio Casanova. São Paulo: Martin Claret, 2015. p. 132.
} 
autoritária. Esta, que ao assumir a culpa pelas ações de seus seguidores cita os seus objetivos maiores e em como é necessário o uso da violência para se alcançar esses objetivos.

Para efeito de comparação, o totalitarismo é uma espécie de autoritarismo mais sofisticado, porque não tem como principal objetivo a tomada do poder, mas sim, o desejo de disseminar a ideologia do movimento, o que será feito por meio da interferência na vida civil dos cidadãos do Estado. Logo, a característica mais marcante do movimento e do regime totalitário, ao contrário do autoritário que não tem esse alcance, é o controle sobre todos os aspectos da vida de qualquer indivíduo que pertença à sociedade. Para obter esse domínio sobre toda a esfera de vida dos indivíduos da sociedade, o totalitarismo os transforma no que é chamado de massa, as pessoas perdem a sua individualidade e tornam-se cidadãos passionais e indiferentes politicamente, que aceitam e praticam a ideologia do regime sem refletir mais profundamente sobre o que realmente estão fazendo. Sendo assim, Arendt elucida o conceito de massa da seguinte forma:

O termo massa só se aplica quando lidamos com pessoas que,
simplesmente devido ao seu número, ou à sua indiferença, ou uama
mistura de ambos, não se podem integrar numa organização
baseada no interesse comum, seja partido político, organização
profissional ou sindicato de trabalhadores. Potencialmente, as
massas existem em qualquer país e constituem a maioria das
pessoas neutras e politicamente indiferentes, que nunca se filiam a
um partido e raramente exercem o poder de voto.

Como Arendt disse, as massas não existem apenas em regimes totalitários, pelo contrário, são comuns em regimes democráticos, sendo que para o totalitarismo chegar ao poder é esse grupo de pessoas politicamente inativas que o movimento primeiramente busca para ser instalado.

O século XX foi marcado por uma era de crises e guerras, tendo destaque as duas grandes guerras mundiais com um intenso progresso na área da tecnologia militar em 1914 e 1930, e do ponto de vista político, o mundo foi atingido por uma onda de autoritarismo. Segundo Boris Fausto:

A partir do fim da Primeira Guerra Mundial, os movimentos e ideias totalitárias e autoritárias começaram a ganhar força na Europa. Em 1922, Mussolini assumiu o poder na Itália; Stálin foi

\footnotetext{
${ }^{5}$ ARENDT, Hannah. Origens do Totalitarismo. Tradução de Roberto Raposo. São Paulo: Companhia de Letras, 2012. p. 439
} 
construindo seu poder absoluto na União Soviética; o nazismo se tornou vitorioso na Alemanha, em 1933. A crise mundial concorreu também para o desprestígio da democracia liberal. ${ }^{6}$

A América Latina também foi afetada, constituída por países de ex-colônias e uma região marcada por desigualdade econômica e social, circunstâncias que em conjunto com o populismo, um tipo de estratégia política que eclodiu geralmente contra a democracia liberal e será explicada posteriormente, contribuíram para encaminhar países latinoamericanos a regimes ditatoriais populistas, dentre os quais estão, por exemplo, o caudilhismo, o peronismo e a ascensão de Getúlio Vargas ao poder no Brasil.

\section{ESTADO DE DIREITO}

A palavra "Estado", de um ponto de vista político interno, pode significar o conjunto de instituições públicas de um país ou, quando colocado num contexto envolvendo a ordem pública internacional ou externo, é um país soberano independente, que pode criar suas próprias regras e governar seu povo dentro da sua extensão territorial sem se subordinar a nenhum outro país, respeitando-se as premissas da ordem internacional.

Para se formar um país ou Estado são necessário três elementos: um território definido; um número de pessoas que tenha hábitos e tradições, no caso, uma cultura semelhante para juntos formarem um povo; e um governo que detém poder e soberania, conforme o exposto pelo jurista português José Joaquim Gomes Canotilho:

Se articularmos a dimensão constitucional interna com a dimensão internacional do Estado poderemos recortar os elementos constitutivos deste: (1) poder político de comando; (2) que tem como destinatários os cidadãos nacionais $($ povo $=$ sujeitos do soberano e destinatários da soberania); (3) reunidos num determinado território. ${ }^{7}$

\footnotetext{
${ }^{6}$ FAUSTO, Boris. História do Brasil. 2. Ed. São Paulo: Editora da Universidade de São Paulo: Fundação do Desenvolvimento da Educação, 1995. p. 353.

${ }^{7}$ CANOTILHO, José Joaquim Gomes. Direito Constitucional e Teoria da Constituição. $7^{\mathrm{a}}$ ed. Coimbra: Almedina, 2003. p. 89-90.
} 
Enquanto o Estado de Direito é a definição anterior complementada pela ideia de que o Estado se subordina e está em conformidade com as leis e o Direito. Nesse sentido, Canotilho expõe:

\begin{abstract}
O princípio do estado de direito é, fundamentalmente, um princípio constitutivo, de natureza material, procedimental e formal (a doutrina alemã refere-se a material-verfahrenmässiges Formprinzip), que visa dar resposta ao problema de conteúdo, extensão e modo de proceder da actividade do estado. Ao decidirse por um estado de direito a constituição visa conformar as estruturas do poder político e a organização da sociedade segundo a medida do direito. ${ }^{8}$
\end{abstract}

A medida do Direito, como disse Canotilho, disciplina o modo de agir do Estado, podendo ele atuar apenas nas formas previstas em sua constituição, elemento inerente a esse tipo de estado, seja de forma negativa, positiva ou como garantidor de direitos. Um Estado de Direito é constitucional e valoriza o princípio da legalidade.

Embora o Regime Autoritário e o Estado de Direito sejam entes antagônicos, esse antagonismo não deve ser interpretado de forma radical, pois mesmo o Estado de Direito mais democrático, depois de ter passado por inúmeras evoluções após eventos históricos marcantes para ser o que é na contemporaneidade, não o é em sua totalidade, e está sujeito a se deparar com vieses autoritários dentro da sua própria instituição.

Isso pode ser indicado, como citado anteriormente9, pela presença da "massa" nos Estados democráticos, que pode ser descrita como uma parte da população que é indiferente, ou seja. Sobre o tema, analisando a democracia contemporânea brasileira, por exemplo, Marcello Baquero discorre:

Observa-se uma adaptação das instituições democráticas a uma prática de uso de procedimentos antidemocráticos que pervertem a representação política, gerando dúvidas e incertezas sobre o futuro da democracia. Isso se verifica não no sentido de favorecer retrocessos institucionais ou rupturas profundas, mas na institucionalização de atitudes de indiferença, apatia e distanciamento da arena política, e na crença de que não há nada que se possa fazer para mudar o atual estado de coisas. Tais atitudes

\footnotetext{
${ }^{8}$ CANOTILHO, José Joaquim Gomes. Direito Constitucional e Teoria da Constituição. $7^{\mathrm{a}}$ ed. Coimbra: Almedina, 2003. p. 243.

${ }^{9}$ ARENDT, Hanna, op. cit. nota 3, pág.4.
} 
podem ser muito mais deletérias ao processo de construção democrática a longo prazo. ${ }^{10}$

Percebe-se que esse problema gera uma "rachadura" no conceito de democracia, um Estado de Direito não pode ser classificado como efetivamente democrático quando a população não expressa a sua opinião sobre as decisões políticas, questiona seus representantes, entende o sistema eleitoral ou cobra por uma solução melhor quando não concorda com a forma optada pelo governo de resolver um problema.

A indiferença política indica uma democracia "jovem" e "frágil”, como no caso das democracias da América Latina, em que o conjunto de conquistas democráticas é menor do que as referências centrais do mundo, identificadas na figura dos países Estados Unidos, França e Alemanha.

Além disso, a população que coloca o governo "em xeque" nas democracias latino-americanas é menos efetiva e por isso, como consequência, é gerada a possibilidade de que aqueles que detém o poder governem apenas para si mesmos e não para o povo, o que demonstraria um viés autoritário dentro dos próprios regimes democráticos.

\section{4 \\ POPULISMO E NEOPOPULISMO NA AMÉRICA LATINA}

O populismo não é um movimento ou regime específico, na verdade, pode ser caracterizado como um tipo de estratégia ou forma de agir na política, Laclau refere-se ao termo como uma "Lógica Política"11 e Bobbio o chama de "Fórmula Política"12, por isso se adequa facilmente a qualquer regime ou movimento, tanto de esquerda quanto de direita, democrático ou não, sendo possível visualizá-lo, por exemplo, no modo de agir do líder ou governante em discursos políticos, no chamamento feito pelo líder ao povo. De acordo com Bobbio:

10 BAQUERO, MARCELlO. CULTURA POLÍTICA PARTICIPATIVA E DESCONSOLIDAÇÃO DEMOCRÁTICA: REFLEXÕES SOBRE O BRASIL CONTEMPORÂNEO. REVISTA SÃO PAULO EM PERSPECTIVA, SÃO PAULO, VOL. 15, N.4, P. 98-104, OUT./DEZ. 2001.

${ }^{11}$ LACLAU, Ernesto. La Razón Populista. Tradução de Soledad Laclau. México: Fondo de Cultura Economica da España, 2008. p. 150.

12 BOBBIO, Norberto. MATTEUCCI, Nicola. PASQUINO, Gianfranco. Dicionário de Política. Brasília: Universidade de Brasília, 1998. p. 980. 


\begin{abstract}
Podemos definir como populistas as fórmulas políticas cuja fonte principal de inspiração e termo constante de referência é o povo, considerado como agregado social homogêneo e como exclusivo depositário de valores positivos, específicos e permanentes. ${ }^{13}$
\end{abstract}

O protagonista principal ou a sua constante é o povo, inclusive Bobbio discorre que, no populismo, a palavra tem um tom de "mito a nível lírico e emotivo"14, e é incentivado tanto sua maior participação política como um relacionamento mais direto entre este e seu líder, comumente carismático e estimado, ou seja, sem a presença de uma instituição mediadora.

Essa "fórmula política" é fundamentalmente conciliadora ${ }^{15}$, porque para o populismo a sociedade não é dividida em classes e sim, entre o povo e o não-povo e para que haja a possibilidade de utilização do populismo, é necessária essa dicotomia, o que será explicado posteriormente neste mesmo subcapítulo. O pertencer ao povo não depende da condição social ou profissional do indivíduo ${ }^{16}$, mas depende da vontade de reivindicar, demandar, soluções da instituição da região ou país, o que Laclau chama de "cadeia equivalencial de demandas insatisfeitas". Considerado como uma massa homogênea, o povo não se apresenta no Populismo como classe ou agregação de classes. ${ }^{17}$

Enquanto o não-povo, segundo Bobbio, é tudo aquilo que é "extrínseco a um povo histórica, territorial e qualitativamente determinado."(BOBBIO, 1998, p. 982), ou seja, que difere do ponto de vista tradicional popular de um país, suas ideologias.

A princípio o não-povo não poderia ser identificado na figura da classe dominante ou dentro da sociedade do país, visto que, nas palavras do mesmo autor, "Populismo e internacionalismo são incompatíveis.”(BOBBIO, 1998, p. 982), entretanto não é concebível uma sociedade em que todos os indivíduos pensem de forma uniforme e igual com uma política em que não há discordâncias e discussões, sendo assim, Bobbio elucida em sua obra "Dicionário de Política" que internamente é possível haver grupos com ideologias diferentes das tradicionais, que podem ser encarados, embora inseridos no mesmo social, como não-povo.

\footnotetext{
${ }^{13}$ Ib., Ibid., p. 981.

${ }^{14}$ Id., Ibid., p. 981.

${ }^{15}$ WILLS apud BOBBIO, Norberto. MATTEUCCI, Nicola. PASQUINO, Gianfranco. Dicionário de Política. Brasília: Universidade de Brasília, 1998. p. 981

${ }^{16}$ BOBBIO, Norberto. MATTEUCCI, Nicola. PASQUINO, Gianfranco. Dicionário de Política. Brasília: Universidade de Brasília, 1998. p. 981.

${ }^{17}$ Id., Ibid., p. 981.
} 
No caso dos países da América Latina pelas suas circunstâncias históricas e sociológicas, o não-povo é difícil de ser visualizado pela intensa miscigenação, não envolvendo apenas uma única em cada país, mas pode ser visualizado na contraposição aos valores e ideologias das classes dominantes pelos grupos historicamente marginalizados na região.

\begin{abstract}
Em alguns países que ainda não concluíram o processo de integração étnica e onde é justamente o elemento popular que apresenta características étnicas heterogêneas como na Argentina e no Brasil, os movimentos populistas não invertem a tendência à fusão étnica, mas a aceleram, favorecendo a integração dos elementos étnicos marginais e contrapondo-os às classes dominantes, mesmo que seja exatamente nestas últimas que as características tradicionais aparecem acentuadas e sublimadas. Em países assim, o povo surge, antes de tudo, como um modo de ser aberto e voluntário. A discriminação está voltada contra certas categorias econômicas e culturais ou então se resolve num racismo de tipo ideológico. ${ }^{18}$
\end{abstract}

Aparentemente, o populismo não apresenta grandes riscos e faz parte de Estados democráticos, contudo, mesmo que caminhe em meio ao voto popular, não se exclui a possibilidade de ser utilizado como meio de "manipulação" da população em regimes democráticos ou ferramenta para o estabelecimento de regimes autoritários, como ocorreu no período da década de 30 no século XX, quando houve uma intensa tendência ao afloramento de ditaduras populistas na América Latina.

Assim, os movimentos nacionais populares latino-americanos, característicos do período populista, se bem que pudessem derivar para formas autoritárias de governo, não implicaram, entretanto, exclusão de formas democráticas de participação política. ${ }^{19}$

No caso da América Latina do século passado, havia uma maioria descrente no sistema político, geralmente formada pelos pobres e as classes médias ou pequena burguesia, grupos de pessoas geralmente desprivilegiados em democracias liberais, à vista disso, os movimentos populares que emergiram englobavam uma ideia nacionalista e contra as oligarquias e o "status quo", isto é, contra uma sociedade dividida em classes. Sobre o populismo latino-americano:

${ }^{18}$ BOBbIO, Norberto. MATTEUCCI, Nicola. PASQUINO, Gianfranco. Dicionário de Política. Brasília: Universidade de Brasília, 1998. p. 982.

19 DEBERT, Guita Grin. Ideologia e populismo: Adhemar de Barros, Miguel Arraes, Carlos Lacerda, Leonel Brizola[online]. Rio de Janeiro: Centro Edelstein de Pesquisas Sociais, 2008. p. 18. 


\begin{abstract}
As massas disponíveis, encontrando condições limitadas para suas aspirações de participação política, viam nestes movimentos antistatus quo o caminho para alcançar maior nível de participação. Por isso mesmo, e para se constituir em um apelo viável às massas populares, o populismo latino americano teve que assumir um caráter nacionalista e anti-oligárquico; e sociais ao invés de removê-las. ${ }^{20}$
\end{abstract}

A verdadeira rachadura presente no populismo, tanto europeu como latino-americano, que o torna um risco no campo político ocorreu quando as classes dominantes da sociedade começaram a utilizá-lo como forma de "dominação" do povo e para isso, como dito anteriormente, é essencial uma dicotomia, sendo mais especificamente entre forças antagônicas da sociedade.

O governo populista é dos "homens" ou do carisma, entretanto isso não significa que seja incompatível com o Estado de Direito, uma vez que existe, com a utilização de discursos e brechas, um populismo em uma forma mais branda nas margens da lei que não necessariamente rompe com a ordem democrática.

É declarado como "governo dos homens", porque a principal contradição do populismo é o líder carismático tentar agradar ambas as forças, visando atrair a atenção de uma maioria descrente e insatisfeita com os desempenhos político-partidários ou com a própria classe política do país, supostamente oferecendo maior participação política, enquanto tenta agradar aqueles que concordam e são a favor do sistema político, a classe dominante, aplicando as políticas favoráveis a esse grupo, que, mesmo que não sendo uma regra, nos principais exemplos do século XX eram liberais econômicas, com o objetivo de alcançar e se manter no poder por meio do apoio das massas.

\footnotetext{
Uma análise mais rigorosa exigiria, como mostra J. A. Moisés (s/d), que o autor estudasse outros grupos e classes sociais que participaram do esquema de alianças populistas. Somente isto nos permitiria entender como, num determinado momento, o populismo foi a forma encontrada pelas classes dominantes para manterem sua dominação. ${ }^{21}$
}

A sua principal contradição pode torná-lo uma ameaça para um Estado de Direito Democrático, porque em sua forma mais branda se tornará um obstáculo ao debate e evolução democrática, como no governo

${ }^{20}$ Id., Ibid., p. 18.

${ }^{21}$ DEBERT, Guita Grin. Ideologia e populismo: Adhemar de Barros, Miguel Arraes, Carlos Lacerda, Leonel Brizola[online]. Rio de Janeiro: Centro Edelstein de Pesquisas Sociais, 2008. p. 19.. 
de Luis Inácio Lula da Silva no Brasil, ou, em um populismo mais intenso como foi a tendência do século XX, poderá futuramente, o líder carismático para assegurar sua posição de poder, guiar o país a um regime autoritário, assim como ocorreu na Argentina com o peronismo, no Brasil com Getúlio Vargas e mais recentemente na Venezuela com Nicolás Maduro. Desenvolvido o conceito de populismo, têm-se como exemplos de movimentos com traços populistas na América Latina: o Bolivarianismo na Venezuela e o governo Cárdenas no México.

As características do populismo tradicional e do neopopulismo são semelhantes, porém há algumas diferenças entre os dois conceitos, sendo a principal as circunstâncias ou elementos históricos. Sobre o tema, o autor Marcello Baquero discorre:

Nas décadas de 1930 e 1950, produziu-se no panorama político da América Latina uma mudança significativa no que diz respeito às orientações políticas dos governos da época. Surgia, nesse período, uma nova modalidade de governo -o populismo. Na virada do milênio, esse fenômeno reaparece e passa a ser denominado neopopulismo. $^{22}$

O populismo tradicional do século $\mathrm{XX}$, surgiu em um "mundo diferente” do neopopulismo do século XXI. Segundo Eric Hobsbawn:

\begin{abstract}
Para melhor ou pior, no século $\mathrm{XX}$ as pessoas comuns entraram na história como atores com seu direito coletivo próprio. Todo regime, com exceção da teocracia, agora derivava sua autoridade delas, mesmo os que aterrorizavam e matavam seus cidadãos em grande escala. O próprio conceito do que antes era moda chamar de "totalitarismo" implicava populismo, pois se não tinham importância o que o "povo" pensava dos que governavam em seu nome, por que então se dar ao trabalho de fazê-lo ter as ideias julgadas adequadas por seus governantes? Os governos que derivavam sua autoridade da obediência irrestrita a alguma divindade, à tradição, ou da deferência das camadas baixas às altas numa sociedade hierárquica, estavam de saída. ${ }^{23}$
\end{abstract}

O neopopulismo floresceu no período de transição entre o século XX e XXI, na década de 90, em uma época em que as democracias do mundo passaram por um momento diferente na política em que eclodiu o

\footnotetext{
${ }^{22}$ BAQUERO, Marcello. Populismo e neopopulismo na América Latina: o seu legado nos partidos e na cultura política. Revista Sociedade e Cultura, Goiânia, v. 13, n.2, pág. 181-192, jul./dez. 2010.

${ }^{23}$ HOBSBAWN, Eric. Era dos Extremos: O breve século XX : 1914-1991. Tradução de Marcos Santarrita. Revisão Técnica de Maria Célia Paoli. São Paulo: Companhia das Letras, 1995. p. 559.
} 
populismo. De acordo com os doutores em ciência política, Silvana Krause e Karl Dieter Hoffmann:

\begin{abstract}
Com os desafios colocados às democracias do século XXI há indicadores de que o esgotamento e os limites das instituições políticas representativas têm gerado e fomentado lideranças políticas com vieses que mesclam estilos do "velho" e conhecido populismo (ex: liderança carismática, messianismo, antiimperialismo, personalismo, nacional-desenvolvimentismo) com algo "novo" (ex: antipolítica, nacionalismo anti-integração global, lideranças suprainstitucionais). ${ }^{24}$
\end{abstract}

Como no populismo, para que o neopopulismo surgisse na transição e continuasse existindo no século XXI, seria necessária uma crise política, mas se no fenômeno anterior a descrença popular se referia a um governo liberal, neste, por outro lado, é dirigida a democracia representativa.

As massas ainda são formadas pelas mesmas classes populares, entretanto no populismo o que era oferecido era apenas a participação política, o que claramente não se concretizava, diferente do neopopulismo em que se acrescenta mais um elemento, segundo Baquero, as políticas públicas de caráter assistencialista.

Dos argumentos acima citados deduz-se que o populismo, como forma de governo, caracteriza-se muito mais pelo seu caráter manipulativo, no qual a ingerência "efetiva" das massas no processo decisório do Estado está, na prática, sempre fora de consideração, ou tem um caráter puramente simbólico e manipulativo. Nas condições atuais, o neopopulismo trabalha com um clientelismo de massas via políticas públicas de caráter assistencialista. $^{25}$

Apesar dos dois fenômenos terem surgido em épocas distintas e existam as diferenças citadas acima, sequer estas ou o passar do tempo excluem a possibilidade do neopopulismo ter um viés autoritário, mesmo nos Estados democráticos, como o populismo, porque o caráter manipulativo disfarçado na figura do líder carismático vestido de salvador da pátria do anterior permanece no "novo" conceito.

\footnotetext{
${ }^{24}$ KRAUSE, Silvana. HOFFMANN, Karl Dieter. Populismo e neopopulismo: teorias, contextos e práxis. Revista Sociedade e Cultura, Goiânia, v. 13, n.2, pág. 167-171, jul./dez. 2010.

${ }^{25}$ BAQUERO, Marcello. Populismo e neopopulismo na América Latina: o seu legado nos partidos e na cultura política. Revista Sociedade e Cultura, Goiânia, v. 13, n.2, pág. 181-192, jul./dez. 2010.
} 
No século XXI, está havendo um processo de desgaste democrático, o que atinge não apenas a Europa ou América do Norte, mas o mundo todo, havendo uma tendência ao radicalismo e um surgimento de vieses autoritários em democracias consolidadas.

Sobre a América Latina, que também passa por esse processo, a maioria dos países que a constituem tem democracias representativas que, como dito anteriormente, podem ser classificadas como "frágeis" e "jovens", e, dentre outros fatores, seu desgaste democrático ocorre principalmente por haver uma constante incapacidade de seus líderes para solucionarem os problemas e atenderem as demandas da população. Com o passar do tempo, as frustrações com a própria instituição acumularam-se e teve início um processo de descrença e indiferença no campo político, tornando essas democracias ainda mais vulneráveis a líderes carismáticos neopopulistas. De acordo com Baquero:

\footnotetext{
Nessas circunstâncias, há uma percepção hegemônica na opinião pública de que o governo e as instituições políticas não são merecedores de confiança por sua incapacidade de processar as demandas sociais. A percepção, por parte da maioria da população, de uma incapacidade institucional para resolver os problemas sociais produz, na prática, uma desinstitucionalização dos mecanismos de mediação política, vulnerabilizando os setores mais frágeis da população para apelos demagógicos e populistas. ${ }^{26}$
}

A consequência da presença desses mecanismos de desprezo pelo princípio democrático e o fenômeno da indiferença política, não é apenas uma maior vulnerabilidade a discursos neopopulistas, inclui também a possibilidade do desgaste democrático e a insegurança popular voltarem seus olhos para outras formas de governo, diferentes das democracias representativas do século XXI, como, por exemplo, um estado autoritário, que aparentemente poderia cumprir as suas expectativas, embora se saiba que o preço a se pagar em direitos e garantias individuais e coletivas seja bem maior.

Ilustrativa do descontentamento gerado por essa situação é a resposta dos cidadãos latino-americanos que apoiariam um ditador

\footnotetext{
${ }^{26}$ BAQUERO, Marcello. Populismo e neopopulismo na América Latina: o seu legado nos partidos e na cultura política. Revista Sociedade e Cultura, Goiânia, v. 13, n.2, pág. 181-192, jul./dez. 2010.
} 
e não um líder eleito, caso eles considerassem que um governo não democrático proporcionasse melhores benefícios econômicos. ${ }^{27}$

O cerne desse viés autoritário se encontra no caráter manipulativo do discurso neopopulista que em um século como o XXI, com o mundo passando por um desgaste democrático, pode ser facilmente utilizado como uma ferramenta para líderes carismáticos "abusarem do poder" de forma legal e aceitável para a massa popular, vulnerável e insegura pela descrença no sistema da democracia representativa.

Trata-se de uma relação política personalizada que não é mediada por nenhuma instituição. Isso produz um discurso fragmentado, incoerente, mas que apela aos sentimentos de uma população descrente nas instituições políticas. ${ }^{28}$

Esse "abuso de poder" significa uma forma de ferir o Estado de Direito aproveitando-se de brechas da própria lei, sem aparentar estar burlando-a para o povo, e podem ocorrer, por exemplo, hipóteses como a de líderes populistas usarem seu carisma para modificarem regras de reeleição como no caso dos governos Morales e Chávez-Maduro na América Latina, respectivamente na Bolívia e Venezuela, que ao terem conquistado o apoio popular por meio de discursos nacionalistas e populistas conseguiram alterar os artigos de suas constituições relativos a reeleição e, em decorrência disso, se estenderem demasiadamente no poder durante um longo período de tempo.

O que torna possível burlar a lei sem levantar uma grande comoção popular é o carisma, que, segundo Weber, é um dos três tipos "puros" de fundamentos da legitimidade política:

O que nos interessa aqui é antes de tudo o segundo daqueles tipos: o domínio graças à devoção do que obedece ao "carisma" puramente pessoal do "líder". Pois aqui se enraíza a ideia da vocação em sua cunhagem extrema. A devoção ao carisma do profeta, do líder na guerra ou do demagogo bem grande na Eclésia ou no Parlamento significa, sim, que ele é considerado pessoalmente como líder interiormente "vocacionado" dos

\footnotetext{
${ }^{27}$ CAPUTO apud BAQUERO, Marcello. Populismo e neopopulismo na América Latina: o seu legado nos partidos e na cultura política. Revista Sociedade e Cultura, Goiânia, v. 13, n.2, pág. 181-192, jul./dez. 2010.

${ }^{28}$ BAQUERO, Marcello. Populismo e neopopulismo na América Latina: o seu legado nos partidos e na cultura política. Revista Sociedade e Cultura, Goiânia, v. 13, n.2, pág. 181-192, jul./dez. 2010.
} 
homens, que esses não se submetem a ele por força dos costumes ou dos estatutos, mas porque acreditam nele. ${ }^{29}$

O carisma, a capacidade de despertar a atenção e persuadir as massas sociais de que têm os mesmos objetivos como o "salvador da pátria", é a maior arma do neopopulismo e um entrave democrático na medida em que o que prevalece nessas circunstâncias é o governo dos homens e não o da lei.

Quando a massa popular é induzida a acreditar fielmente em um líder, não havendo cobranças ou questionamentos, comete-se o mesmo erro político do passado na época do Absolutismo, motivo pelo qual o Estado de Direito foi criado, dá-se liberdade exacerbada ao Poder Executivo e um governante sem os freios da legalidade eventualmente desrespeita os direitos de seus cidadãos e torna-se autoritário.

Por isso, há a possibilidade do neopopulismo do século XXI ser um risco para o Estado de Direito Democrático, posto que ao "encantar" a população, não há garantias que o líder neopopulista cumprirá suas expectativas ou apenas oferecerá medidas de caráter assistencialista para aparentar fazê-lo, além de que com a insegurança popular, a indiferença e descrença no sistema da democracia representativa, uma das consequências do processo de desgaste, há uma vulnerabilidade que pode ser explorada e facilitar a aceitação daqueles a medidas ilegais com o objetivo de se manterem no poder, existindo ainda a hipótese de posteriormente, assim como na Venezuela, haver a transição para um regime autoritário.

\section{CONSIDERAÇÕES FINAIS}

Em sentido amplo, o Estado autoritário traduz-se como todo regime em que no momento da transmissão do poder, por meios coercitivos, um líder ou grupo o "usurpa" ou assume, concentrando todo o poder político em suas mãos, sendo que o dever de obediência dos governados ao governante(s) se funda na força ou no medo. Nesse contexto, a população e as organizações representativas são as maiores prejudicadas por, respectivamente, perderem participação política e serem desfeitas ou apenas aparentar funcionar formalmente.

\footnotetext{
${ }^{29}$ WEBER, Max. Ciência e Política: Duas Vocações. Tradução e notas de Marco Antonio Casanova. São Paulo: Martin Claret, 2015. p. 65.
} 
Não se confunde autoritarismo com totalitarismo, posto que o primeiro é gênero e o segundo uma espécie mais sofisticada, além de seus objetivos e a forma como afetam a vida dos cidadãos serem diferentes, uma vez que o regime totalitário busca a constante disseminação da ideologia para o mundo todo e a dominação completa sobre todos os aspectos da vida civil de seus seguidores, ao contrário do autoritário.

Por outro lado, há o Estado de Direito, que é fundado na legalidade e submete o próprio Estado e aqueles que detêm o poder ao império da lei para que não sejam cometidos abusos ou coerção contra a população, como os ocorridos no século XX. Essa forma de governo evoluiu ao longo do tempo e na contemporaneidade, se manifesta como o Estado Democrático de Direito na forma da democracia representativa, havendo uma maior proteção não apenas aos direitos civis, políticos e sociais dos cidadãos, mas também aos coletivos e difusos.

Embora o Regime Autoritário e o Estado de Direito sejam entes antagônicos, esse antagonismo não deve ser interpretado, como foi explicado ao longo do trabalho, de forma intransigente. Não existe uma modalidade de democracia absoluta, podendo ser classificada como mais ou menos efetivas, sujeita a ter vieses autoritários dentro da sua instituição na forma, por exemplo, da convivência entre os fenômenos do populismo e neopopulismo latino-americanos, objeto de estudo do presente trabalho, com o princípio da legalidade no qual originalmente se fundamenta o Estado de Direito se fundamenta, surgindo a figura de um Estado de Direito formal ou aparente.

O populismo é uma estratégia política que aflorou contra a democracia liberal no século $\mathrm{XX}$, na época fragilizada pelas crises econômicas, havendo uma descrença por parte do povo, sendo este $\mathrm{O}$ fundamento do populismo, no sistema político. Quando integrado no Estado Democrático de Direito, respeitado os limites previstos na lei pelo líder populista, na condição de um populismo moderado, há a possibilidade de ser utilizado como forma de manipulação da população, ou, por outro lado, se mais intenso ou radical, como ferramenta para o estabelecimento de regimes autoritários, como ocorreu na década de 30 e 50 com a eclosão de ditaduras populistas na América Latina, posto que ambas as hipóteses são possíveis pela presença do líder carismático, inerente a essa estratégia política.

A maior contradição presente na "fórmula política" populista é o líder agradar simultaneamente as forças antagônicas da sociedade por meio 
de seu carisma, traço que permanece mesmo no neopopulismo, que no contexto do século passado, aparentava dar maior participação política ao povo, enquanto na verdade a limitava e tomava medidas, geralmente liberais, favoráveis a classe dominante.

Ao longo da pesquisa, concluiu-se que o neopopulismo do século XXI é uma continuação do populismo do século XX, tendo como única diferença as circunstâncias históricas em que ambos surgiram. O neopopulismo aflora em um momento de desgaste da democracia representativa, o povo está inseguro sobre o sistema político e mais vulnerável a discursos populistas carismáticos, que oferecem políticas públicas assistencialistas e asseguram a capacidade daquele que discursa de governar.

No passado ou presente, ambas as estratégias políticas, que são flexíveis e podem se adequar tanto a ditaduras quanto a democracias, possuem um viés autoritário embutido no caráter manipulativo do discurso populista. O carisma permite que o governante em questão, através de brechas como, por exemplo, a possibilidade de alteração das regras de reeleição constitucionalmente como ocorreu na Bolívia e na Venezuela, burle as leis sem aparentar fazê-lo para o povo, que acredita fielmente na figura do seu "salvador da pátria".

Com esse estudo sobre os vieses autoritários nas democracias contemporâneas da América Latina, não se espera encerrar o assunto abordado, porém sim, chamar atenção para a questão e reafirmar a importância de encarar os vieses autoritários com que o Estado de Direito convive e fortalecer os pilares da democracia, além de ter um legislador ou administrador político que seja cauteloso e não exceda o limite, no caso usando o neopopulismo, entre o Estado Democrático de Direito e o Estado Autoritário para que não se atente, como já aconteceu anteriormente na história, contra os direitos dos cidadãos e a ordem democrática.

\section{REFERÊNCIAS BIBLIOGRÁFICAS}

AQUINO, Rubim Santos Leão de; LEMOS, Nivaldo Jesus Freitas de; Lopes, Oscar Guilherme Pahl Campos. História das sociedades americanas. 11. ed. Rio de Janeiro: Record, 2007.

ARENDT, Hannah. Origens do Totalitarismo. Tradução de Roberto Raposo. São Paulo: Companhia de Letras, 2012. 
BAQUERO, Marcello. Cultura Política Participativa e Desconsolidação Democrática: Reflexões sobre o Brasil Contemporâneo. Revista São Paulo em Perspectiva, São Paulo, vol.15, n.4, p. 98104, out./dez. 2001.

BAQUERO, Marcello. Populismo e neopopulismo na América Latina: o seu legado nos partidos e na cultura política. Revista Sociedade e Cultura, Goiânia, v. 13, n.2, pág. 181-192, jul./dez. 2010.

BOBBIO, Norberto; MATTEUCCI, Nicola; PASQUINO, Gianfranco; Dicionário de Política. Brasília: Universidade de Brasília, 1998.

BONAVIDES, Paulo. Ciência Política. 24ª ed. São Paulo: Malheiros, 2017.

CANOTILHO, José Joaquim Gomes. Direito Constitucional e Teoria da Constituição. $7^{\mathrm{a}} \mathrm{ed}$. Coimbra: Almedina, 2003.

DEBERT, Guita Grin. Ideologia e populismo: Adhemar de Barros, Miguel Arraes, Carlos Lacerda, Leonel Brizola[online]. Rio de Janeiro: Centro Edelstein de Pesquisas Sociais, 2008.

FAUSTO, Boris. História do Brasil. 2. Ed. São Paulo: Editora da Universidade de São Paulo: Fundação do Desenvolvimento da Educação, 1995.

HOBSBAWN, Eric. A Era das Revoluções: 1789 - 1848. Rio de Janeiro: Editora Paz e Terra. 1977.

HOBSBAWN, Eric. Era dos Extremos: O breve século XX : 1914-1991. Tradução de Marcos Santarrita. Revisão Técnica de Maria Célia Paoli. São Paulo: Companhia das Letras, 1995.

KRAUSE, Silvana. HOFFMANN, Karl Dieter. Populismo e neopopulismo: teorias, contextos e práxis. Revista Sociedade e Cultura, Goiânia, v. 13, n.2, pág. 167-171, jul./dez. 2010.

LACLAU, Ernesto. La Razón Populista. Tradução de Soledad Laclau. México: Fondo de Cultura Economica da España, 2008. Pág. 150.

MORAES, Alexandre de. Direito Constitucional. 13. Ed. São Paulo: Atlas, 2003.

PARK, Thais Hae Ok Brandini; GUILLAUMON, Talita Hae Sun Brandini Park. Dicionário jurídico: principais termos e expresses de uso cotidiano e sua legislação. Termos e palavras latinas na prática forense. Abreviaturas. 5. ed. Leme: Cronus, 2016.

WEBER, Max. Ciência e Política: Duas Vocações. Tradução de e notas: Marco Antonio Casanova. São Paulo: Martin Claret, 2015. 